\title{
ELDERLY VISUAL TASK PERFORMANCE BY DIFFERENCES ON READING MEDIA AND LAMP POSITION IN A ROOM
}

\author{
Luciana Kristanto $^{1^{*}}$, Gunawan Tanuwidjaja ${ }^{1}$, Joshua Antonio, Liana Maria Callista Lie, \\ Marcellino Sebastian, Theresia Chany \\ ${ }^{1}$ Lecturer of Architecture Department, Petra Christian University, Siwalankerto 121-131 Surabaya, INDONESIA \\ *Corresponding author; Email: lucky@petra.ac.id
}

\begin{abstract}
This research aimed to find out how lighting influence visual task performance of the elderly.The experiment was done on the table with different lamp position and by giving mark on the landolt ring chart printed on different reading media. Three position, the front, the middle and the back were the variables for lamp position, whilst different reading medias were the brown paper usually used for newspaper, the white silk uncoated paper or 'HVS' paper and the white gloss paper. The lamp were TL5 LED with $4000{ }^{\circ} \mathrm{K}$ and $6500^{\circ} \mathrm{K}$ color temperature. The illumination level maintained specificly at $250-325$ lux range. The respondents were 12 elderly with 58 years as the mean age. The result findings, for newspaper, the best position for speed was the front with 1.15 second per stroke; followed by the back with 1.18 second per stroke; and the middle got the lowest result with 1.4 second per stroke. For the HVS and glossy paper with higher luminance, the best for speed was the middle position that was the darkest in illumination, with 1.25 second per stroke for HVS and 1.3 second per stroke for glossy. The worst result was the back with 1.4 second per stroke for HVS and 1.36 second per stroke for glossy paper. For accuracy, the best for newspaper was the front, $96.02 \%$. For the HVS paper, the middle and the back position has got the same highest accuracy, $90.45 \%$. For the glossy paper, the middle position has got the highest accuracy, $91.62 \%$. The visual task performance result, for the newspaper, the front position has got the highest score, followed by the back position that have brighter in illumination, but the score was lowest for the middle position. Contrary, for white HVS and white gloss paper, which get almost identic result, the middle position which was rather dark in illumination was the best, while the front and the back position were worse in visual task performance score. So that can be concluded that the higher illumination level was not always give the best to visual task performance; but depending to the user and the kind of paper or reading media as well.
\end{abstract}

Keywords: Elderly visual task performance; lamp position; reading media.

\section{INTRODUCTION}

Nowadays we found the growth of elderly people in their productive age still. In offices and universities, elderly people with visual activities such as reading books, writing articles, even making technical drawing are usual. Beside their capability in such kind of visual activities, their eyes as the media are decreasing toward ages. The cornea is not clear, but yellowish. The eyes accomodation getting slower as well. Through the normal ageing process, even in the absence of cataracts (clouding the lens), the lens becomes less transparent, blocking additional light from entering the eye, and changing the color of the light that does get through (Sekuler \& Sekuler, 2000; Sekuler, 2010). This condition actually increases functioning difficulties, in the older age. And disability became an important feature as the demographics of societies change and more people live to an old age (Hartley et al., 2011). According to this background, this research aimed to find out how lighting influence visual task performance of the elderly. This research study how lamp position, different reading media and lamp color temperature influence the visual task of the elderly. Findings from this research can give suggestion to architect, interior designer and building owner to give the best table to lamp position according to media uses, especially for elderly occupants.

\section{AGING AND VISION}

As people age, their vision is affected by changes both to their eyes and their brains. The average pupil size decreases with age, so that less light enters the eye, and this reduction in light is compounded by changes in the structure of the lens. Through the normal ageing process, even in the absence of cataracts (clouding the lens), the lens becomes less transparent, blocking additional light from entering the eye, and changing color of the light that does get through. Changes to the lens and intraocular media also increase light scatter, reducing the contrast of the retinal image. These structural changes to the lens also make it more difficult to focus on close objects as we age; this change in accomodative ability-the ability to change the optical 
power of the eye to focus on objects at different distances- is known as presbyopia, and is normal part of the ageing process (Sekuler \& Sekuler, 2000; Sekuler, 2010). Fiorentini, Porciatti, Morrone \& Burr (1996), found that ageing causes a small and unspecific decline of the response of the visual system to luminance and colour contrast. Another research of Facchin, Daini \& Zavagno (2017), found that luminosity thresholds of GE (Glare Effect) for elderly was higher than those for young (this result was contrary from their original expectations) and it was suggesting a non-direct relationship between luminosity perception and discomfort glare. Another research on retail store lighting for elderly consumers found that older adults have more difficulty with warmer lighting when value contrasts were reduced. Besides, the older adults perceived the higher color temperature light source as less cool than younger adults did. (Park \& Farr, 2007)

\section{EFFECTS OF LIGHTING ON VISION}

The effects of lighting on vision is the most obvious impact of light on humans. The stimulus presented to the visual system by any task can be described by five parameters: visual size, luminance contrast, color difference, retinal image quality and retinal illumination. These five parameters imply that it is the interaction between the object to be seen, the background against which it it seen, and the lighting both object and background determine the stimulus the object presents to the visual system. It is the stimulus and the operating state of the visual system that determine the level of visual performance achieved. This visual performance then contribute to task performance. It is important to point out that visual performance and task performance are not necessarily the same. Visual performance is the performance of the visual component of the task. Task performance is the performance of the complete task. Tasks in which visual performance is large or critical will be more sensitive to changes in lighting conditions than tasks where the visual component is small or unimportant (Boyce, 2011).

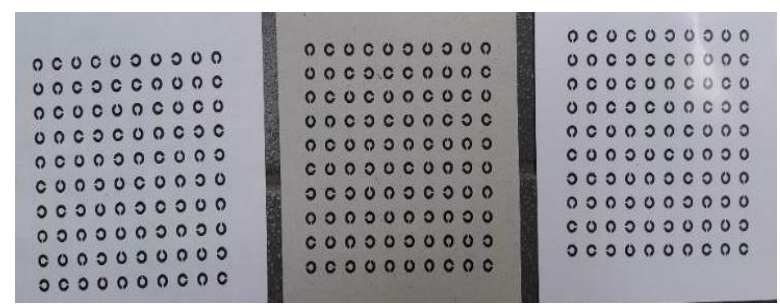

Fig. 1. Landolt 'C' ring printed on HVS paper, newspaper and glossy paper
The visual task here was reading the Landolt ring chart printed on different papers. According to Boyce (1981), many different features of printing can be expected to influence the ease of reading; for example, the typeface of the print, its quality, its contrast, its size and its layout are likely to be important. Grimm, Rassow, Wesemann, Saur \& Hilz (1994), stated that initial attempts to standardize the determination of visual acuity date back to Snellen's work in 1862. Subsequently, Green (1868) and Monoyer (1875) examined letters of different typefaces to evaluate their suitability for visual acuity estimation. Landolt recognized the necessity of a standard optotype that displays smaller differences in legibility than the different letters of the alphabet. His "circle interromptu" was accepted 21 years later as a standard optotype at the International Ophthalmological Congress in Naples. As the reference optotypes, the Landolt ring or Landolt ' $\mathrm{C}$ ' is the most widely accepted reference optotype for use in the vision testing laboratory. It is an interrupted circle whose stroke width and gap width are one fifth of its outer diameter. It major advantage is that it contains only one, easy measured, element of critical detail that represents the only difference between its various presentations, usually 4 or 8 orientations. (International Council of Ophthalmology, 1988). The advantages of the Landolt ring are: (1) a single characteristic feature in all eight directions of presentation; (2) low directional dependency in fully corrected patients; and (3) the negligible influence of shape recognition compared with letters or numerals. (Grimm, et. al., 1994) That's why used here the Landolt ring, in order to hinder the typeface variable.

\section{ILLUMINANCE, LUMINANCE CONTRAST, GLARE, COLOR TEMPERATURE, AND LAMP POSITION RECOMMENDATION}

In working spaces in Indonesia, a uniform illuminance at 250-350 lux and a relative color temperature of daytime white light at $3300^{\circ} \mathrm{K}$ to $>5300^{\circ} \mathrm{K}$ was recommended (Badan Standardisasi Nasional, 2001). A study of mid-scale office buildings in Japan found that for illuminance, a range between 200 to 800 lux, and for the color temperature, a range between $3000^{\circ} \mathrm{K}$ to $5500^{\circ} \mathrm{K}$ was preferred (Ono, 2012). A field survey on actual conditons of light environment in mid-scale office buildings in Japan found the highest percentage of frequency of the ceiling illumination usage, $91.3 \%$ always use ceiling illumination; $4.6 \%$ often use ceiling illumination; while only $10 \%$ of the office occupants used task lighting (Mochizuki \& Koike, 2010). The CIBSE and 
IESNA recommend that luminance contrast between light sources and adjacent areas, and anywhere within the normal field of view should be less than 20:1 and 40:1 respectively (CIBSE, 1994). Other recommendations suggest that luminance contrast between task surface, immediate surrounds, and distant areas should be less than the ratios 1:3:10 (Arup, 2007 in Amirkhani, Garcia-Hansen, Isoardi \& Allan, 2017). Creating the luminance contrast between 11:1 and 12:1 on the window wall in an office room with $45 \%$ window to exterior wall ratio using supplementary LED light can improve subjective assessments of window appearance; and significantly reduce discomfort glare from windows (Amirkhani, Hansen, Isoardi, \& Allan, 2017). Huebner et al. (2016) suggest the manipulation of the ambient light color as a tool for energy-saving in buildings; while temperatures could be lower under a reddish/yellowish illumination in the heating season, or, conversely, be kept higher under bluish illumination in the cooling season. According to the lamp position theory, the parallel and perpendicular lamp position influence the visual comfort of the visual task on the table below. The parallel position created a severe glare problem, while the perpendicular was much more diserable and effective (McGuinnes, Reynolds \& Stein, 1980). From the preliminary measurement found that the critical was the table position persistently below the lamp that tend to reflected glare, that's why this position was researched further.

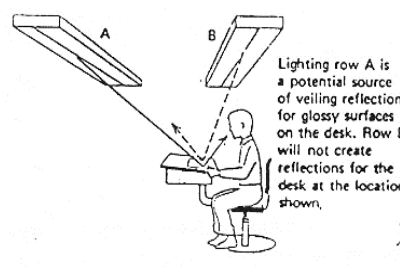

(a)

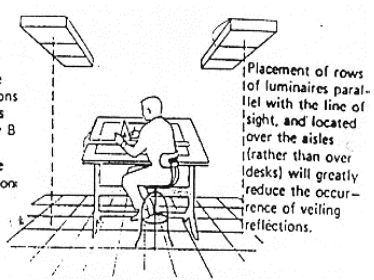

(b)
Fig. 2. Parallel (a) and perpendicular (b) lamp position (McGuinnes, Reynolds, Stein, 1980)

\section{METHODOLOGY}

This research has done by field measurement by doing visual task on the table. The visual task size was the Landolt ring for $40 \mathrm{~cm}$ distance (reading distance on the table) at 4 orientations. The outer ring diameter was $2.92 \mathrm{~cm}$ and the stroke and the gap was one-fifth of this dimension. Used here three kinds of printed paper as reading media that has been widely used as book-printed paper. They were white silk uncoated paper widely known as the 'houtvrij schrijfpapier' (HVS), the gloss paper, and the newspaper. The reflectance factor of HVS paper was $76 \%$, the gloss paper was $77 \%$, and the newspaper was $55 \%$. The luminance of the HVS paper was $10 \mathrm{~cd} / \mathrm{m} 2$, the gloss paper was $12.2 \mathrm{~cd} / \mathrm{m} 2$, while the newspaper was 4.6 $\mathrm{cd} / \mathrm{m} 2$. The reading table was from dark brown teakwood shiny polished, $0.75 \mathrm{~m}$ height. The respondent were 12 elderly with 58 year as the mean age, in their comfortable reading behaviour, with or without glasses. The test room was a hall with table to lamp position shown in figure 3 . The wall as the room boundaries were far away and without exterior wall, in order to make sure that the lamp gives the most influence to the table. The ceiling height was $3.40 \mathrm{~m}$, white paint smooth finished. The maintained illumination ranging from 315 lux (front position), 255 lux (middle position), to 325 lux (back position).
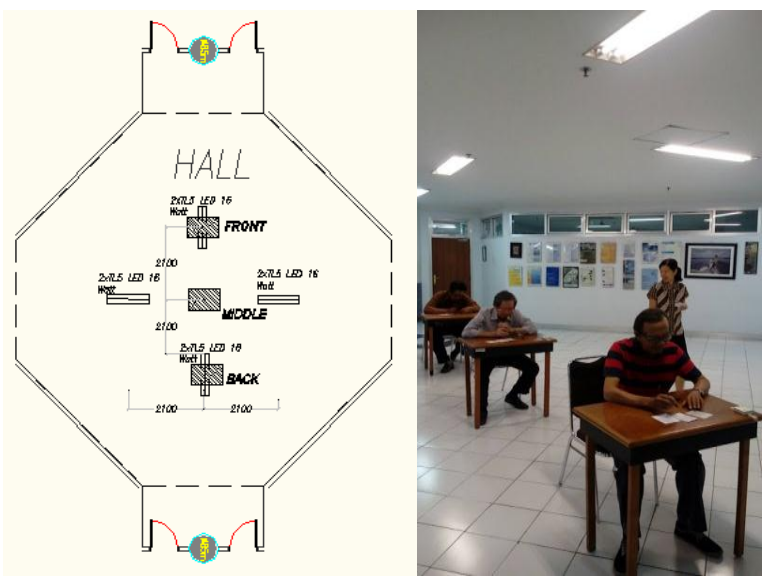

Fig. 3. Room layout and Measurement Position

The measurement done by three respondent at the same time. While seating, each respondent asked to read through the chart on each kind of paper and give mark/stroke in same way all the rings that have a gap orientated in a specified direction. They started at the same time as instructors given; and when one task paper was finished, they raised their hands and the time was recorded by the instructor. Then they done the same way to two other papers. Each respondent must do the visual task for all position; the front, the middle and the back position, but with different order. After they finished all the position, they filled into the questionnaire.

\section{RESULTS and DISCUSSION}

Result from this research reported in speed aspect, accuracy aspect, visual task performance, and the color temperature preference as well. Speed is given by the number of rings correctly marked divided by the total time taken. Speed is then stated in stroke/second. Accuracy is given by the number of rings correctly marked divided by the total number of 
rings that could have been marked. Speed and accuracy are then multiplied to form what is called the performance score. The color temperature preference got from the questionnaire.

\section{Speed Aspects}

\section{Speed vs Paper}

From figure 4, found that for doing task on the newspaper that was brown color and rather textured, the result for the fastest speed was at the front with 0.52 stroke/second, meant it's needed 1.15 second per stroke; then the back was 0.51 stroke/second or needed 1.18 second per stroke; whereas the middle position was the lowest with 0.43 stroke/second, meant that it's needed 1.4 second for doing one stroke. This reading media need more light to read, so that the front and the back position was more suitable, while the middle position as the darkest was not.

For the white HVS paper, the fastest speed was at the middle with 0.48 stroke/second, meant it's needed 1.25 second for doing one stroke; followed by the front with 0.46 stroke/second or 1.3 second per stroke, whereas the back position got 0.43 stroke/ second or 1.4 second per stroke. Since this reading media had high luminance but diffuse, so the bright condition at the back can brought to reflected glare. The front and the middle position was more suitable for this paper.

For the white gloss paper that has highest luminance, the middle position was the fastest speed with 0.46 stroke/seconds or meant that 1.3 second needed for doing one stroke; followed by the front with 0.45 stroke/ second or 1.33 second per stroke; while the back get the longest time, 0.44 stroke/ second or needed 1.36 second per stroke. Found that this highest luminance paper got the lowest result. By the result we could analyze that this paper might reflect more light from lamps to many direction and different angles, than two other papers, so that this paper was the most difficult to read.

\section{Speed vs Position}

According to the position, the result shown that the front and the back position have averagely the same character in speed. Whereas the easiest to the most difficult paper were the newspaper, the white HVS and the white gloss paper. But at the middle position that was the darkest, the newspaper was the most difficult paper to read; while the white gloss was easier, and the white HVS was the easiest paper to read.
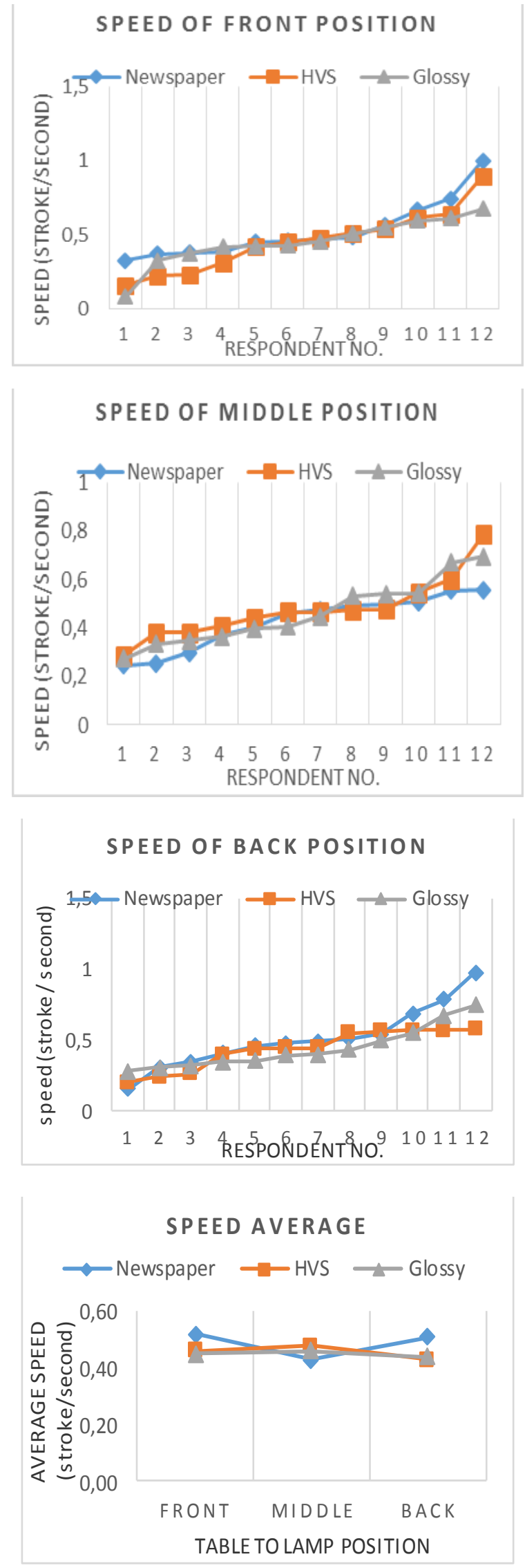

Fig. 4. Speed Average according to Paper and Table to Lamp Position 


\section{Accuracy Aspect}
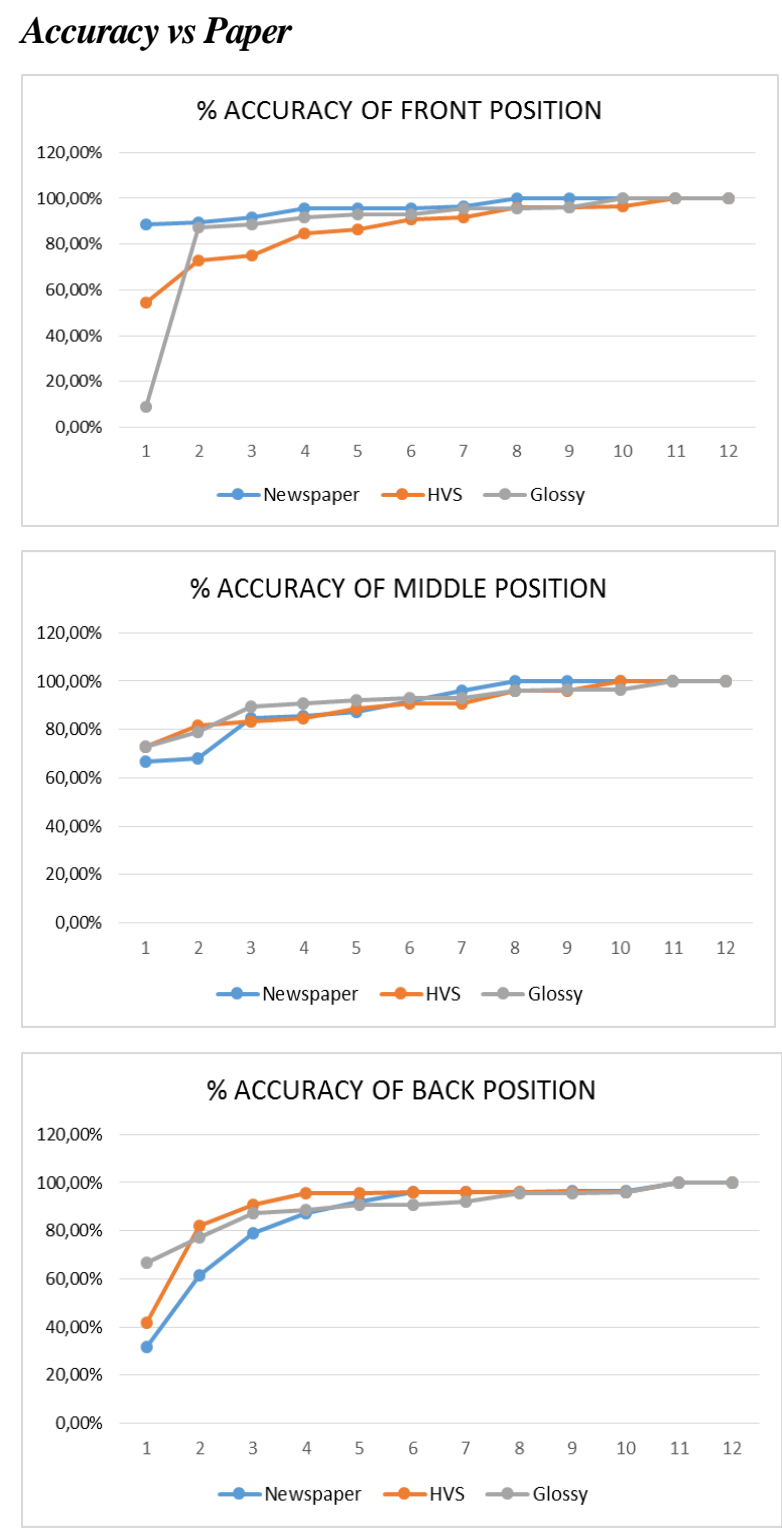

\% AVERAGE ACCURACY, POSITION, PAPER

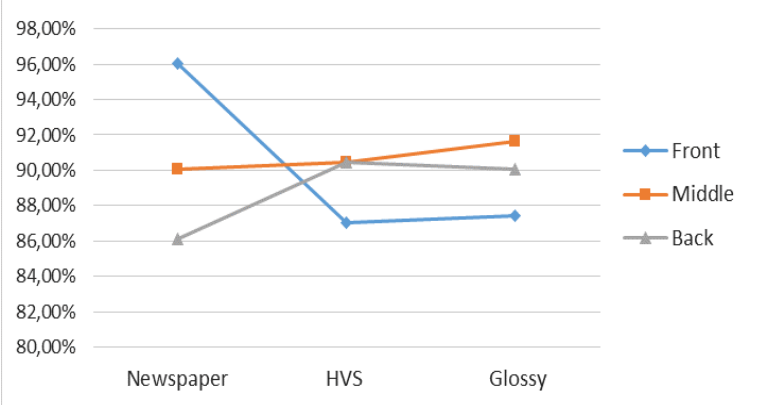

Fig. 5. Percentage (\%) of Accuracy, Paper, Position

From figure 5, accuracy for reading newspaper get the highest percentage at the front, $96.02 \%$ and the middle $90.04 \%$. While at back the accuracy was the lowest, $86.08 \%$.
White HVS paper that has high luminance but diffuse get the lowest in accuracy at the front $87.02 \%$. At the middle and the back, the accuracy got the same point, $90.45 \%$.

White gloss paper with highest luminance has got $87.43 \%$ accuracy at the front, $91.62 \%$ at the middle, and $90.09 \%$ at the back. By the result, found that white gloss paper accuracy was the highest at the middle.

\section{Accuracy vs Position}

Averagely, at all position, accuracy in reading newspaper was the highest, $90.71 \%$, followed by white gloss paper with $89.71 \%$ accuracy, while white HVS paper has got the lowest in accuracy, $89.31 \%$.

\section{CONCLUSION}

From the speed and accuracy toward different lamp position and different reading media, can be summarized the visual task performance score for the elderly as Table 1.

This result shown that for the elderly, visual task performance score of the newspaper was highest at the front position, followed by the back position that have brighter in illumination, but the score was lowest for the middle position. Contrary, for white HVS and white gloss paper, which get almost identic result, the middle position which was rather dark in illumination was the best, while the front and the back position were worse in visual task performance score.

From the questionnaire, the front position chosen best in illumination by 5 of 12 respondents. The back chosen by 2 of 12 respondents. Two from 12 respondent chose the middle as best position as well. Whereas 3 from 12 respondents felt all position had the same illumination. Also stated by 6 from 12 respondents that the middle was too dark, and the back was too bright ( 5 of 12 respondents).

By this visual task test and user preference result, can be concluded that the higher illumination was not always give the best to visual task performance; but depending to the user and the kind of paper or reading media as well.

For the color temperature, 5 of 12 respondents chose cool daylight as the best ambience; only 3 of 12 respondents chose the neutral white as their favorite ambience. Other respondents abstain or feel no differences regarding this.

This research still need to be continued on different age respondents to give recommendation for the best visual acuity according to occupant's activity with considering to contrast sensitivity of the table to room ambience. 
Table 1. Visual Task Performance Score

\begin{tabular}{|c|c|c|c|c|c|c|c|c|c|}
\hline & \multicolumn{3}{|c|}{ Newspaper } & \multicolumn{3}{|c|}{ White HVS paper } & \multicolumn{3}{|c|}{ White gloss paper } \\
\hline & Speed & Accuracy & $\begin{array}{c}\text { Visual } \\
\text { performance } \\
\text { score }\end{array}$ & Speed & Accuracy & $\begin{array}{l}\text { Visual } \\
\text { performance } \\
\text { score }\end{array}$ & Speed & Accuracy & $\begin{array}{c}\text { Visual } \\
\text { performance } \\
\text { score }\end{array}$ \\
\hline Front & 0.52 & $96.02 \%$ & 0.50 & 0.46 & $87.02 \%$ & 0.40 & 0.45 & $87.43 \%$ & 0.40 \\
\hline Middle & 0.43 & $90.04 \%$ & 0.38 & 0.48 & $90.45 \%$ & 0.43 & 0.46 & $91.62 \%$ & 0.42 \\
\hline Back & 0,51 & $86.08 \%$ & 0.44 & 0.43 & $90.45 \%$ & 0.39 & 0.44 & $90.09 \%$ & 0.39 \\
\hline
\end{tabular}

\section{ACKNOWLEDGEMENT}

This research done by funding from United Board for Christian Higher Education Association.

\section{REFERENCES}

Amirkhani, M., Garcia-Hansen, V., Isoardi G. \& Allan A. (2017). An energy efficient lighting design strategy to enhance visual comfort in offices with windows. Energies, 10(1126), pp.116.

Arup, O.N. \& Arup, L. (2007). Lighting: Technical Review. London, UK : RIBA Publishing.

Badan Standardisasi Nasional. (2001). Konservasi Energi Pada Sistem Pencahayaan. Indonesian National Standard (SNI) 03-6197-2000.

Boyce, P.R. (1981). Human Factors in Lighting. London : Applied Science Publishers.

Boyce, P.R. (2011). On measuring task performance. Coloration Technology Journal, 127, pp.101113.

Chartered Institution of Building Services Engineers. (1994). Code for Interior Lighting. London, UK: CIBSE

Facchin, A., Daini, R. \& Zavagno, D. (2017). The glare effect test and the impact of age on luminosity thresholds. Frontiers in Psychology, 8(1132), pp.1-5. doi: 10.3389/fpsyg.2017.01132

Fiorentini, A., Porciatti, V., Morrone, M.C. \& Burr, D.C. (1996). Visual ageing: Unspecific decline of the responses to luminance and colour. Vision Res., 36(21), pp.3357-3566. Elsevier

Hartley, S., et al. Swanson, M., Thomas, M. \& Qiu,Z., eds.(2011). World Report On Disability 2011. World Health Organization.
Huebner, G.M., et al. (2016). Saving energy with light? Experimental studies assessing the impact of colour temperature on thermal comfort. Energy Research \& Social Science, 15, pp.4557.

International Council of Ophthalmology. (1988). Visual acuity measurement standard. Presented to the Consilium Ophthalmologicum Universale and approved for distribution on October 5th, 1984. Italian Journal of Ophthalmology, II/ I, pp.1-15.

Mc Guinnes, W.J., Reynolds, J.S. \& Stein, B. (1980). Mechanical and Electrical Equipment for Buildings. $6^{\text {th }}$ edition. New Jersey : John Wiley and Sons, Inc.-USA.

Mochizuki, E. \& Koike, K. (2010). Field survey on actual conditions of light environment in midscale office building in Japan. Journal of Light and Visual Environment, 34(3), pp.157-164.

Ono, et al. (2012). Development of an intelligent lighting system using LED ceiling lights into an actual office. Electronics and Communications in Japan, 95(10), pp.54-63. (translated from Denki Gakkai Ronbunshi, 131-A/5, May 2011, pp.321-327).

Park, N-K. \& Farr,C.A. (2007). Retail store lighting for elderly consumers: an experimental approach. Family and Consumer Sciences Research Journal, 35(4), pp.316-337. doi: 10.1177 / $1077727 X 07300096$

Sekuler, R. \& Sekuler, A.B. (2000). Vision and Ageing in Encyclopedia of Psychology.[SAGE journal], pp.180-183.

Sekuler, A.B. (2010). Ageing and Vision in Encyclopedia of Perception. [SAGE reference], pp.2. Accessed on September 22, 2016. http://dx.doi. org/10.4135/9781412972000.n10 